\title{
NMDA Receptor-Dependent Regulation of Axonal and Dendritic Branching
}

\author{
Li-Jen Lee, Fu-Sun Lo, and Reha S. Erzurumlu \\ Department of Cell Biology and Anatomy, Louisiana State University Health Sciences Center, New Orleans, Louisiana 70112
}

In the rodent trigeminal principal nucleus (PrV), trigeminal afferent terminals and postsynaptic cells form discrete modules ("barrelettes") that replicate the patterned array of whiskers and sinus hairs on the snout. Barrelette neurons of the PrV relay whisker-specific patterns to the contralateral thalamus and, subsequently, to the primary somatosensory barrel cortex. Genetic impairment of NMDA receptor (NMDAR) function blocks development of barrelettes in the PrV. Underlying cellular and functional defects are not known. Here, we examined morphological differentiation of whisker afferents, dendritic differentiation of barrelette cells, and their electrophysiological properties in mice with genetic perturbations of the essential subunit NR1 of NMDARs. We show that in NR1 gene knock-down (KD) and knock-out mice, whisker afferents begin their embryonic development normally but, over time, fail to segregate into patches, and instead they develop exuberant terminal arbors spanning most of the PrV. Postnatal NR1KD barrelette cells, with significantly reduced NMDA currents, retain their membrane and synaptic properties but develop longer dendrites with no orientation preference. These results indicate that NMDARs regulate growth of presynaptic terminal arbors and postsynaptic dendritic branching, thereby leading to consolidation of synapses and patterning of presynaptic and postsynaptic elements.

Key words: barrelettes; transgenic mice; trigeminal afferents; trigeminal principal nucleus; membrane properties; pattern formation

\section{Introduction}

In the first relay station of the rodent trigeminal pathway principal nucleus (PrV), whisker afferent terminals form discrete patches of terminals that replicate the patterned array of the whiskers on the snout (Erzurumlu and Jhaveri, 1992). Afferent patterning is detected by select sets of postsynaptic neurons, trigeminothalamic projection or "barrelette" neurons, which orient their dendrites toward discrete patches of trigeminal afferent terminals. As a result, whisker-specific barrelette units are formed ( $\mathrm{Ma}$ and Woolsey, 1984; Bates and Killackey, 1985; Ma, 1993). PrV barrelette cells convey these patterns to the thalamic barreloids and consequently to the somatosensory barrel cortex (Woolsey and Van der Loos, 1970; Van der Loos, 1976; Killackey and Fleming, 1985; Erzurumlu and Jhaveri, 1990; Senft and Woolsey, 1991). Lesions of the whisker follicles, or the branch of the trigeminal nerve innervating them, irreversibly alter or abolish patterns in the PrV and upstream somatosensory centers during a critical period in development (Belford and Killackey, 1980; Durham and Woolsey, 1984; Woolsey, 1990; O'Leary et al., 1994).

Cellular and molecular mechanisms underlying patterning of presynaptic terminals and barrelette cell dendrites are unknown. Neural activity, in particular NMDA receptor (NMDAR)-

Received Dec. 1, 2004; revised Jan. 20, 2005; accepted Jan. 22, 2005.

This research was supported by National Institutes of Health-National Institute of Neurological Disorders and Stroke Grant NS37070. We thank H. Cline for critical reading of this manuscript and T. Iwasato and S. Tonegawa for providing the transgenic mice.

Correspondence should be addressed to R. S. Erzurumlu, Department of Cell Biology and Anatomy, Louisiana State University Health Sciences Center, 1901 Perdido Street, New Orleans, LA 70112. E-mail: rerzur@|suhsc.edu. D0I:10.1523/JNEUROSCI.4902-04.2005

Copyright $\odot 2005$ Society for Neuroscience $\quad 0270-6474 / 05 / 252304-08 \$ 15.00 / 0$ mediated activity, is an essential player in development of whisker-specific patterns in the PrV. Targeted deletion of the NMDAR1 (NR1) (Li et al., 1994) or NR2B (Kutsuwada et al., 1996) subunit genes of NMDARs, or transgenic reduction of NR1 subunit expression (Iwasato et al., 1997), produced mice with no whisker patterning in the $\operatorname{PrV}$, whereas a full array of whiskers were present on the snout. To gain insight into cellular mechanisms of pattern deficits, we studied the development of whisker afferents in the PrV of NR1 knock-out (KO) and NR1 knockdown (KD) mice during the critical period of pattern formation. We next analyzed electrophysiological properties and dendritic patterning of barrelette neurons in postnatal NR1KD mice. Our results show that although membrane properties of barrelette neurons remain unchanged in transgenic mice, their dendritic differentiation and terminal arbor fields of their presynaptic partners arriving from whisker follicles change dramatically.

\section{Materials and Methods}

Animals. NR1KD mice were generated as described previously (Iwasato et al., 1997). Crossing transgenic founders with $N R 1^{+/-}$mice (Li et al., 1994) led to incorporation of the NR1 transgene into $N R 1^{+/-}$strain. $N R 1^{-1-}$ mice carrying NR1 transgene have $70-80 \%$ reduction of $N R 1$ expression (Iwasato et al., 1997). These mice were originally reported as "NR1 ${ }^{-1-} \mathrm{LTg}^{+/+}$" mice; here, we refer to them as NR1KD mice. In the present study, normal mice (C57BL/6) and mice carrying the NR1 transgene were used as controls.

Genotype analysis was performed by PCR using the DNA samples extracted from the tail. Oligo sequences designed for NR1 and Neo were used (Iwasato et al., 1997). PCR products were resolved on a $\%$ agarose gel. Neo oligo pair gives a $280 \mathrm{bp}$ fragment, and NR1 oligo pair gives 240 bp (normal NR1 gene) and 160 bp (NR1 transgene) fragments.

All animal handling was in accordance with a protocol approved by the 

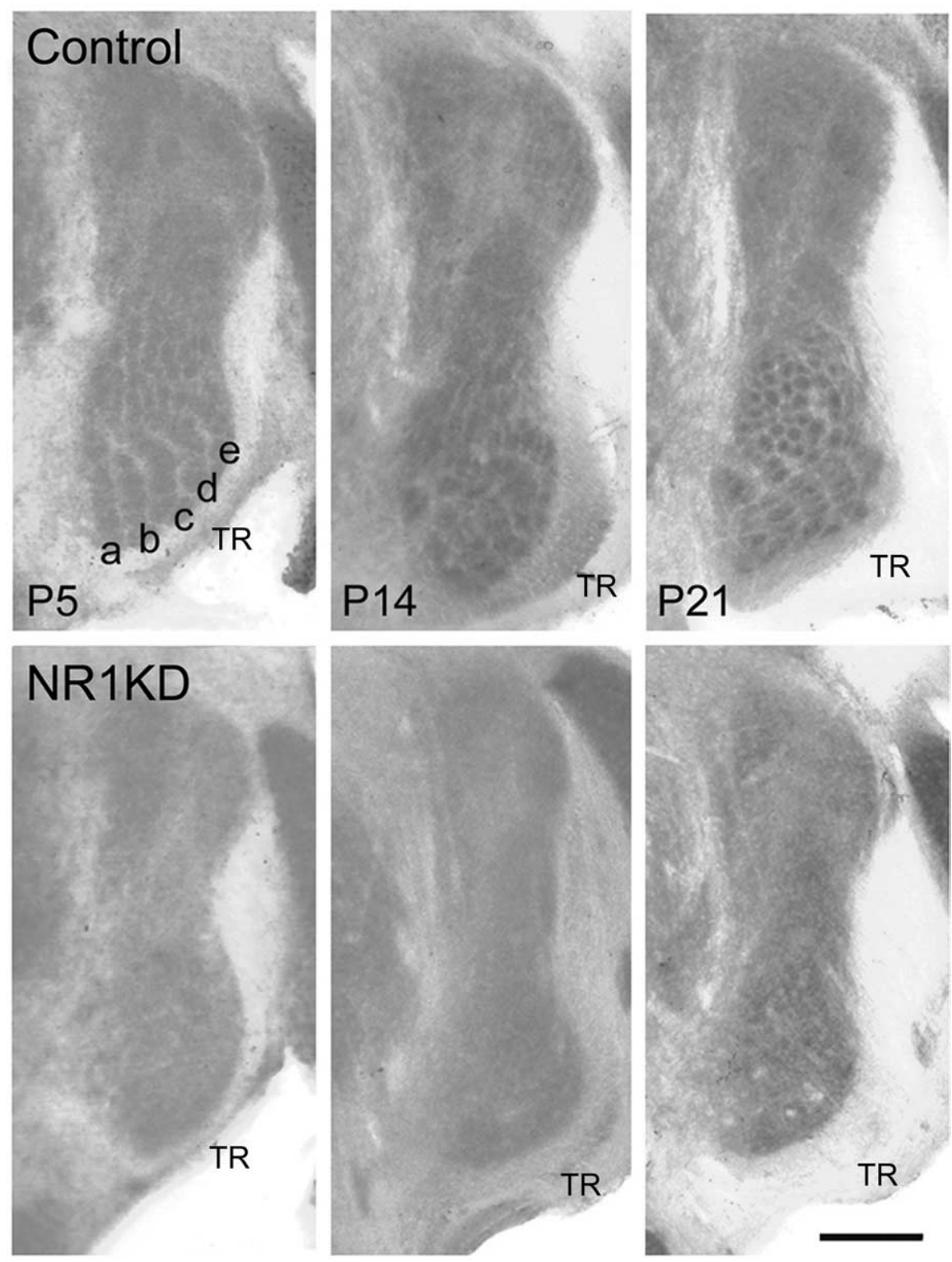

Figure 1. Absence of whisker-specific patterns in NR1KD mice. Cytochrome oxidase histochemistry reveals barrelette patterns in control PrV at P5, P14, and P21, whereas the patterns are absent in NR1KD mice at all ages. Barrelette rows corresponding to whisker rows a-e are indicated in control PrV. All micrographs are from coronal sections and are oriented the same way, with lateral to the right and dorsal to the top. TR, Trigeminal tract. Scale bar, $500 \mu \mathrm{m}$.

Louisiana State University Health Sciences Center Animal Use and Care Committee.

\section{1,1'-Dioctodecyl-3,3,3',3'-tetramethylindo-}

carbocyanine perchlorate labeling. Control, NR1KO, and NR1KD mice [embryonic day 15 (E15) to postnatal day 5 (P5)] were perfused transcardially with phosphate buffer (PB), followed by $4 \%$ paraformaldehyde. A small crystal of 1,1' -dioctodecyl-3,3,3',3' -tetramethylindocarbocyanine perchlorate (DiI) (Molecular Probes, Eugene, OR) was placed into one whisker follicle on the snout. Samples were kept in an incubator at $37^{\circ} \mathrm{C}$ for $2-3$ weeks. The brainstems were sectioned horizontally by vibratome (VT1000S; Leica, Nussloch, Germany) at a thickness of $300 \mu \mathrm{m}$. Pictures at different focal planes were taken from fluorescent microscope by Coolsnap camera (Photometrics, Tucson, AZ) with MetaVue program (Universal Imaging, Downingtown, PA). DiI-labeled single axons were then reconstructed from composite pictures. All of the single axons emanating from the trigeminal tract with their terminal arbors were included in the study. Cases with neighboring axons leaving the tract and entering the brainstem trigeminal complex and those in which there were overlapping terminal fields were not included in our analyses.
Histology. Mice were given an overdose of sodium pentobarbital and perfused transcardially with $4 \%$ paraformaldehyde in $0.1 \mathrm{M} \mathrm{PB}, \mathrm{pH} 7.4$. Brains were removed and placed in the same fixative overnight. After cryoprotection in 30\% sucrose in PB for $2 \mathrm{~d}, 90-\mu \mathrm{m}$-thick coronal sections through the brainstem were taken from P5, P14, and P21 NR1KD and control mice. All chemicals were purchased from Sigma (St. Louis, MO). Sections were incubated in cytochrome oxidase $(\mathrm{CO}$ ) reaction solution (in $\mathrm{mg} /$ $\mathrm{ml}$ : 0.5 cytochrome $c$, 40 sucrose, 0.5 diaminobenzidine, in $\mathrm{PB}$ ) at $37^{\circ} \mathrm{C}$ in a shaker incubator for 6-8 h. Staining of CO histochemistry enabled us to visualize PrV boundaries and barrelette patterns.

To visualize PrV neurons, the Golgi-Cox impregnation method was used (Datwani et al., 2002). Brainstem samples from $4 \%$ paraformaldehyde-perfused animals were immersed into impregnation solution [mixture of solution A (1.0 g of potassium dichromate and $1.0 \mathrm{~g}$ of mercuric chloride in $85 \mathrm{ml}$ of distilled water) with solution B $(0.8 \mathrm{~g}$ of potassium chromate and $0.5 \mathrm{~g}$ of sodium tungstate in $20 \mathrm{ml}$ of distilled water] at room temperature for $6-8 \mathrm{~d}$. After impregnation, the specimens were cryoprotected in $30 \%$ sucrose for $3 \mathrm{~d}$. Frozen sections were cut on sliding microtome at $200-300 \mu \mathrm{m}$. Sections were collected and passed through $15 \%$ ammonium hydroxide (EM Science, Gibbstown, NJ) for $30 \mathrm{~min}$ and Kodak fixative solution (Eastman Kodak, Rochester, NY) for 15 min and then rinsed thoroughly in distilled water. Sections were then counterstained with cresyl violet, dehydrated through a series of alcohol, and mounted with Depex (Electron Microscopy Sciences, Washington, PA).

Morphometric analyses. Impregnated neurons were examined under a Nikon (Tokyo, Japan) light microscope with a $40 \times$ lens and reconstructed using a drawing tube. Images of neurons were then scanned at 300 dots per inch and standardized and stored in Adobe Photoshop 7.0 (Adobe Systems, San Jose, CA). In this study, we adopted the terminology used by Ohara and Havton (1994). The dendrite derived directly from the soma is the first-order branch or primary dendrite. The daughter branches arising from that are second-order branches, and so on. The point at which a dendrite gives rise to two daughter branches is called a bifurcation node. The distance from the soma or a bifurcation node to the next node is called the segment length. Termination of a dendrite is called an ending.

For morphometric analysis of the dendrites, soma size and area covered by the dendritic tree were measured from the two-dimensional display by MetaVue program. The number of primary dendrites, bifurcation nodes, and endings were counted manually. To examine the dendritic tree orientation, endings were marked, and the greatest angle between the two furthest endings was measured. A neuron with $\geq 75 \%$ of its endings falling into one quadrant was designated as a neuron with selective orientation. Otherwise, the neuron was classified as a symmetrical neuron. The concentric sphere method of Sholl (1953) was used to analyze dendritic branching patterns. Briefly, concentric spheres of a constant interval, $10 \mu \mathrm{m}$, were brought over each cell, and the cell was oriented with the center of the soma as the origin; the dendrogram was prepared accordingly. Intersections of spheres and dendrites of different orders were counted. The position (between two rings) and order of bifurcation nodes and endings were also noted. The number of branches 
and the length of segments were measured and analyzed into orders. Segment lengths were measured by tracing the dendritic segments from one bifurcation point to another (or to the tip of the last segment) with the use of MetaVue program. Our dendritic segment measurements were done from two-dimensional reconstructions of dendritic fields of neurons embedded in 2- to $300-\mu \mathrm{m}$-thick sections; therefore, they do not reflect absolute values for dendritic segment length, but they are nevertheless informative for comparisons between control and knock-down cases.

Electrophysiology. For electrophysiological recordings, NR1KD and control mice (P7-P13) were anesthetized with Fluothane and killed by decapitation. Brains were removed and immersed in cold $\left(4^{\circ} \mathrm{C}\right)$ artificial CSF (ACSF) bubbled with $95 \% \mathrm{O}_{2}$ and $5 \% \mathrm{CO}_{2}$. Brainstems were then embedded in $2 \%$ agar and cut into $400-\mu \mathrm{m}$-thick transverse sections with a vibratome. After 2-4 h of incubation in ACSF at room temperature, slices containing the $\mathrm{PrV}$ were transferred into a submerged-type recording chamber and perfused continuously $(>2$ $\mathrm{ml} / \mathrm{min}$ ) with oxygenized ACSF at room temperature. Whole-cell recordings were then made as described previously (Lo and Erzurumlu, 2001, 2002). Voltage-clamp was performed with patch electrode filled with Csbased solution. AMPA receptor-mediated and NMDA receptor-mediated EPSCs were induced by maximal stimulation of the trigeminal tract. The AMPA receptor-mediated EPSC is identified by voltage clamping at $-70 \mathrm{mV}$ in the presence of $10 \mu \mathrm{M}$ bicuculline. The NMDA receptor-mediated EPSC is isolated by voltage clamping at $+40 \mathrm{mV}$ in the presence of $10 \mu \mathrm{M}$ bicuculline and $25 \mu \mathrm{M}$ DNQX, an AMPA receptor antagonist.

\section{Results}

Lack of barrelette patterns in the PrV of NR1-deficient mice

In normal mouse PrV, barrelette patterns appear at approximately P2-P3 and are consolidated by P5 (Ma, 1993). NR1KO mice die shortly after birth because of respiratory problems. When parturition is blocked by terbutaline injections to the pregnant dam and the pups are delivered $2 \mathrm{~d}$ past the normal gestation period (equivalent to P2), barrelettes are absent in NR1KO mice (Li et al., 1994). Transgenic expression of low levels of NR1 in the NR1KO background "rescues" postnatal lethality, and in these (NR1KD) mice (Iwasato et al., 1997), barrelettes never form (Fig. 1). Consequently, barreloids in the thalamus and barrels in the somatosensory cortex are absent, although these animals have a normal set of whiskers and display whisking behavior. The underlying cellular defects could involve differentiation of whisker-specific afferent terminals in the PrV, dendritic development of barrelette cells, or synaptic communication and electrophysiological properties of PrV neurons. First, we examined the developmental differentiation of whisker-specific trigeminal afferent terminals in the PrV of NR1KO and NR1KD mice and then electrophysiological properties of barrelette neurons and their dendritic differentiation in NR1KD mice.

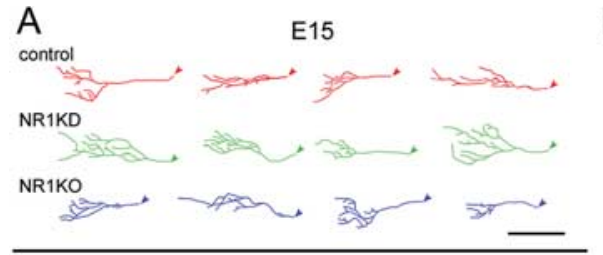

B
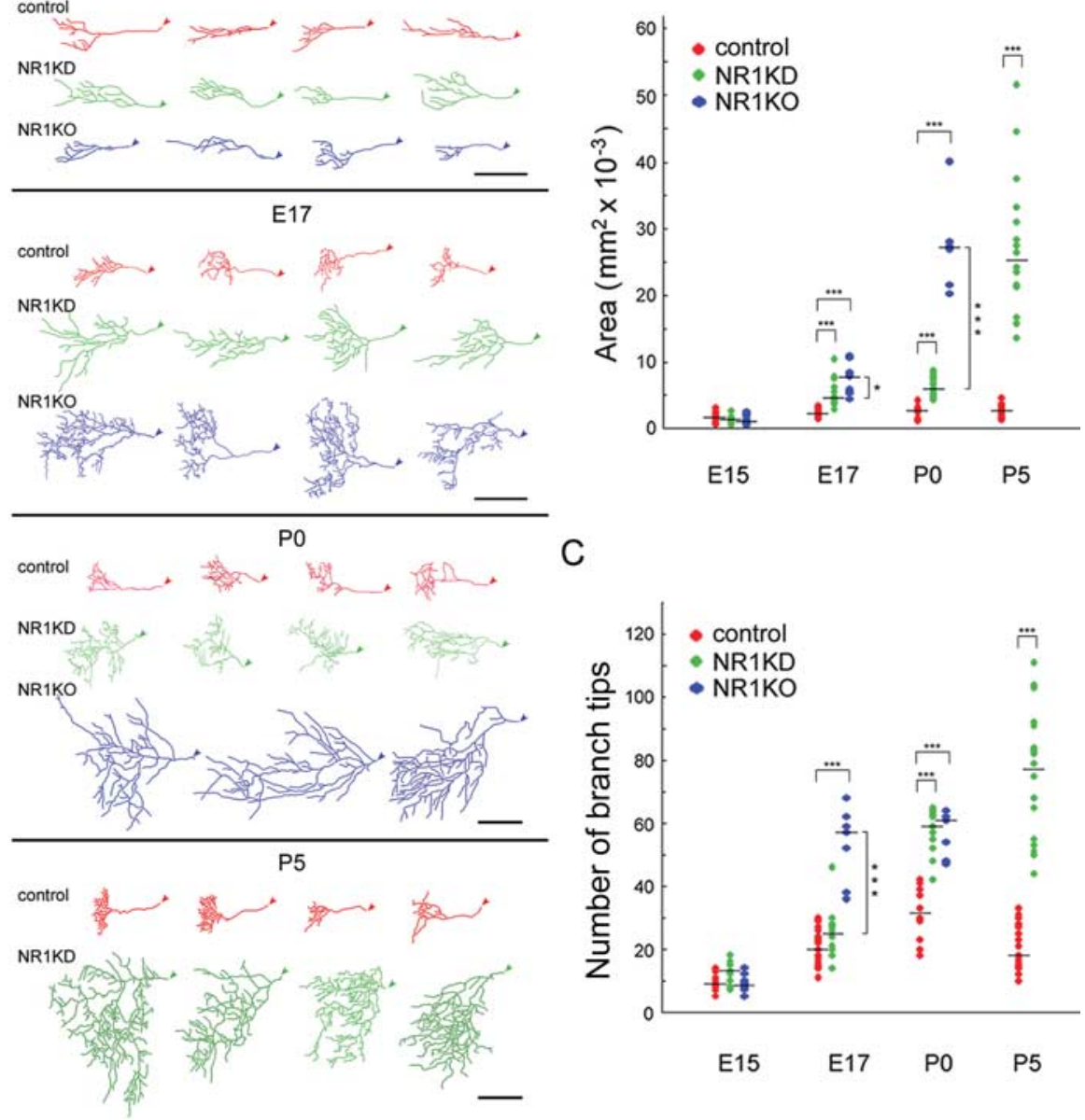

C

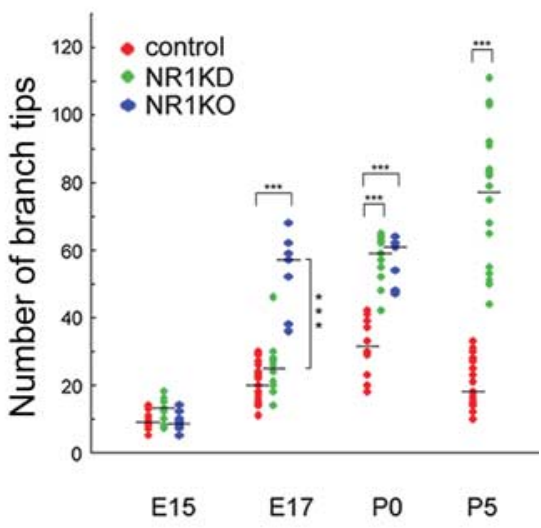

Figure 2. Development of whisker afferent terminal arbors in the PrV. $\boldsymbol{A}$, Whisker-specific trigeminal afferents begin arborizing in the PrV by E15, and the arborization patterns are similar in control and NMDAR-deficient mice. At E17, there is a notable expansion of terminal arbors in the mutant PrV. By P0, terminal arbors in PrV are expansive in NR1KO mice and much larger than never develop segregated patches. Arrowheads indicate the parent axon emerging from the trigeminal tract. All axons are oriented the same way, with the position of the central trigeminal tract (lateral) to the right and rostral to the top. Scale bar, 100 two-dimensional reconstruction. There is no significant difference among control, NR1KD, and NR1K0 afferents at E15; however, from E17 and on, NR1KD and NR1KO terminals have significantly enlarged compared with the controls. NR1KO terminal areas are trigeminal afferent arbors. The number of branch tips shows no differences among the control, NR1KD, and NR1KD cases at E15. By terminals have more branches than controls $(p<0.001)$. A horizontal bar is used to represent the mean of each group. Significant differences are indicated by asterisks $\left({ }^{*} p<0.05 ;{ }^{* * *} p<0.001\right.$; Student's $t$ test).

\section{Exuberant axonal arborization in NR1 mutant PrV}

Trigeminal ganglion axons invade the developing whisker fields at approximately E10 in the mouse, and their central processes lay down the trigeminal tract in the brainstem by E13 (Stainier and Gilbert, 1990). After the establishment of the central tract, trigeminal axons emit radial collaterals into the brainstem trigeminal nuclei and begin forming whisker-specific patchy terminals by E15. We placed tiny DiI crystals into individual whisker follicles of E15, E17, P0, and P5 mice. We used four lines of mice as follows: NR1KO, NR1KD, wild-type (C57BL/6), and C57BL/ $6^{\text {NRItransgene }}$ mice. The latter two groups were pooled as controls. In all lines of mice, initial arborization patterns in the PrV are simple and similar at E15 (Fig. 2A). By E17, trigeminal arbors in control cases show patchiness and elaboration of small terminal branches. In contrast, a much larger and highly branched termi- 
nal arbor field is emergent in NR1KD and specifically in NR1KO cases (Fig. $2 A, B$ ). At the time of birth, the whisker afferent arbors are the largest and most complex in NR1KO mice and conspicuously larger in NR1KD animals in comparison with controls. By $\mathrm{P} 5$, which is after the end of the critical period for whisker lesioninduced morphological plasticity (Woolsey, 1990), trigeminal terminal arbors in the NR1KD PrV occupy a fivefold larger area than those in control cases (Fig. 2A,B). Quantitative analyses of the afferent arbors and the number of branch tips between E15 and $\mathrm{P} 5$ revealed that there is no significant difference between the controls and NR1-deficient PrV at E15 (Fig. 2B,C). However, significant differences in all of the measured arbor parameters are evident in NR1KO mice from E17 onward and are also seen in the postnatal NR1KD mice (Fig. $2 B, C$ ). Clearly, widespread terminal arbors, increased branch tips, and overlapping distribution of whisker afferents within the PrV of NR1KO and NR1KD mice are major defects that contribute to the absence of barrelette patterns (Fig. 1).

\section{Membrane properties and synaptic response of barrelette neurons in PrV}

Barrelette neurons of the PrV are the major trigeminothalamic projection neurons, and they alone convey the whisker-specific neural pattern template to the ventrobasal thalamus and subsequently to the primary somatosensory barrel cortex (Killackey and Fleming, 1985; Erzurumlu and Jhaveri, 1990). To determine whether intrinsic membrane properties and synaptic responses of barrelette neurons were altered in NR1-deficient mice, we performed electrophysiological recordings in the PrV of postnatal NR1KD and control mice. We could not use NR1KO mice, because they die after birth as a result of respiratory failure ( $\mathrm{Li}$ et al., 1994). Barrelette neurons from the earliest postnatal ages to maturity typically have an A-type $\mathrm{K}^{+}$conductance $\left(I_{\mathrm{A}}\right)$ when the membrane potential is depolarized after hyperpolarization, leading to delayed sodium spikes (Lo et al., 1999). This is not altered in NR1KD barrelette neurons (Fig. 3A). Thus, membrane properties of barrelette neurons are preserved in NR1KD PrV.

Synaptic responses were recorded from barrelette neurons after trigeminal tract stimulation (Fig. $3 B, C$ ). An EPSP-IPSP sequence is induced in control and NR1KD barrelette neurons, indicating that excitatory and inhibitory synaptic connections are present (Fig. 3B). Voltage-clamp analyses reveal that the excitatory response is mediated by AMPA and NMDA receptors (Fig. $3 C)$. However, in NR1KD neurons, the amplitude of NMDARmediated responses is significantly smaller than control neurons $(24.1 \pm 5.6$ vs $130.4 \pm 16.5 \mathrm{pA} ; p<0.005)$, thus confirming $80 \%$ reduction of NMDAR function.

In NR1KD mice, intrinsic membrane properties and synaptic responses of barrelette neurons are not altered, other than an $80 \%$ reduction in the NMDA component of the EPSCs. Their presynaptic partners form diffuse and widespread terminal arbors that span multiple barrelette domains. How does this affect dendritic arbors and patterning of barrelette neurons?

\section{Reduced NMDAR function disrupts dendritic differentiation} and patterning of barrelette neurons in the PrV

Barrelette patterns are readily visualized by use of routine cytochrome oxidase histochemistry or Nissl stains (Fig. 4A). On average, barrelettes have a $\sim 10 \mu \mathrm{m}$ wall and a $\sim 30-40 \mu \mathrm{m}$ center (Fig. $4 A$, asterisks). We used the Golgi heavy metal impregnation technique (Datwani et al., 2002) to reveal the morphological details of the PrV neurons (Fig. $4 B$ ). Small barrelette neurons form the barrelette wall and display selective dendritic orientation (Fig.

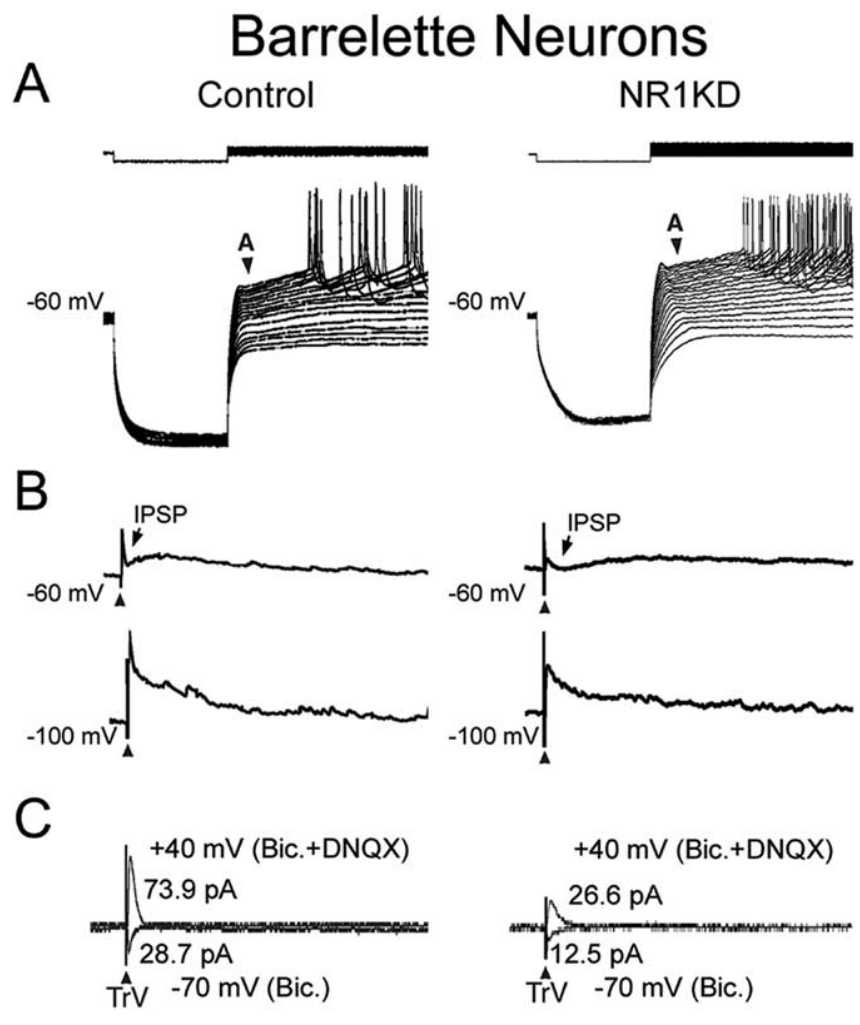

Figure 3. Membrane properties and synaptic responses of barrelette neurons. $\boldsymbol{A}$, Voltage responses to intracellular current injection. Top trace, Current pulses; bottom trace, voltage responses. An A-type conductance (denoted by A) is activated by different depolarizing current pulses after membrane hyperpolarization. Note that the generation of $\mathrm{Na}{ }^{+}$spikes is delayed by A-type conductance. Barrelette neurons in PrV of both control and NR1KD mice display a prominent A-type conductance. $\boldsymbol{B}$, Synaptic responses of control and NR1KD barrelette neurons. Weak stimulation of the trigeminal tract that is subthreshold for induction of $\mathrm{Na}^{+}$spikes evokes an EPSP-IPSP sequence. Note that the IPSP has reversed in polarity at membrane hyperpolarization (top vs bottom traces). $C$, The excitatory responses in barrelette neurons are mediated by both AMPA and NMDA receptors. The AMPA receptor-mediated EPSC is characterized by voltage clamping at $-70 \mathrm{mV}$ in the presence of $10 \mu \mathrm{m}$ bicuculline (Bic.). The NMDAR-mediated EPSC can be isolated, whereas voltage is clamped at $+40 \mathrm{mV}$ in the presence of $10 \mu \mathrm{m}$ bicuculline and $25 \mu \mathrm{m}$ DNQX, an AMPA receptor antagonist. Note that the NMDA receptor-mediated EPSCS of NR1KD neurons are smaller than that of the control mice. TrV, Trigeminal tract stimulation.

$4 B$, arrow) toward trigeminal afferent terminal patches. Large interbarrelette neurons have extensive dendritic fields covering multiple barrelettes (Fig. 4B, arrowheads). Because P14 is well beyond the critical period for barrelette development, and dendrites of PrV cells have acquired their mature characteristics, we chose this time point to examine the dendritic differentiation of barrelette neurons. A total of 87 barrelette neurons (control, $n=$ 40 ; NR1KD, $n=47$ ) from the whisker representation area of the $\mathrm{PrV}$ were examined. We measured various morphometric parameters (Table 1) and determined dendritic projections and the orientation preference of dendritic trees (Fig. 4). Sholl analysis (Sholl, 1953) was applied to reveal the complexity and distribution of the dendrites (Fig. 5A-C). Finally, we plotted numbers of dendritic branches and segment lengths for each dendritic order (Fig. 5D,E).

Soma sizes of barrelette cells in control and NR1KD mice are similar (Table 1). Normally, barrelette neurons have three primary dendrites emanating from the soma (Table 1), and their dendritic fields are restricted and oriented toward the barrelette centers (Fig. 4C,E,F). NR1KD barrelette neurons usually have 
four primary dendrites (Table 1) that radiate in all directions from the soma (Fig. $4 D, E)$. Most of the barrelette neurons $(85 \%)$ in NR1KD PrV do not have orientation preference (Fig. $4 F$ ).

Sholl analysis (Sholl, 1953) revealed that the dendrites of NR1KD barrelette neurons have more proximal $(10 \mu \mathrm{m})$ intersections (Fig. 5A), because NR1KD neurons have more primary dendrites. However, the dendrites of NR1KD barrelette neurons formed fewer branches (Fig. $5 B, D$ ), especially at higher orders, giving significantly reduced branch number beyond the fifth order and resulting in less dendritic orders and smaller total branch point numbers (Table 1). Although the total number of terminal endings in NR1KD barrelette neurons is comparable with control cells (Table 1), their distribution is remarkably different. In NR1KD barrelette neurons, some of the terminal endings are located beyond 50 $\mu \mathrm{m}$ from the soma (Fig. $5 C$ ). This is because their dendrites have longer segments (Fig. $5 E$ ), causing a $35 \%$ increase in the total dendritic length (Fig. $5 E^{\prime}$ ) and more intersections at distal regions (Fig. 5A). Consequently, NR1KD barrelette neurons have much larger dendritic fields (Table 1) (3.4-fold larger dendritic fields than those of control cells). Overall, NR1KD barrelette neuron dendrites show little or no orientation preference, have longer segments, and have fewer highorder branches, indicating that NMDAR-mediated mechanisms play a major role in dendritic sculpting, complexity, and orientation.

\section{Discussion}

Our results indicate that neural activitymediated by the NMDARs plays a significant role in presynaptic terminal and postsynaptic dendritic sculpting in the first relay nucleus of the mouse trigeminal somatosensory pathway. Recently, we reported that in NR1KD mice, there is a significant reduction in the volume of the $\operatorname{PrV}(24.4 \%)$ and similar volumetric reductions in its thalamic target, ventroposteromedial nucleus (25.5\%) (Lee and Erzurumlu, 2005). Ongoing studies are aimed at determining whether such volumetric reductions in these nuclei are a consequence of pronounced cell death. Increased arboreal span of trigeminal terminals and expansion of dendritic fields of barrelette neurons found in the present study are cellular defects/anomalies that accompany areal shrinkage of the nucleus itself. Despite severe defects in morphological differentiation of NMDAR-deficient PrV, barrelette cells re-
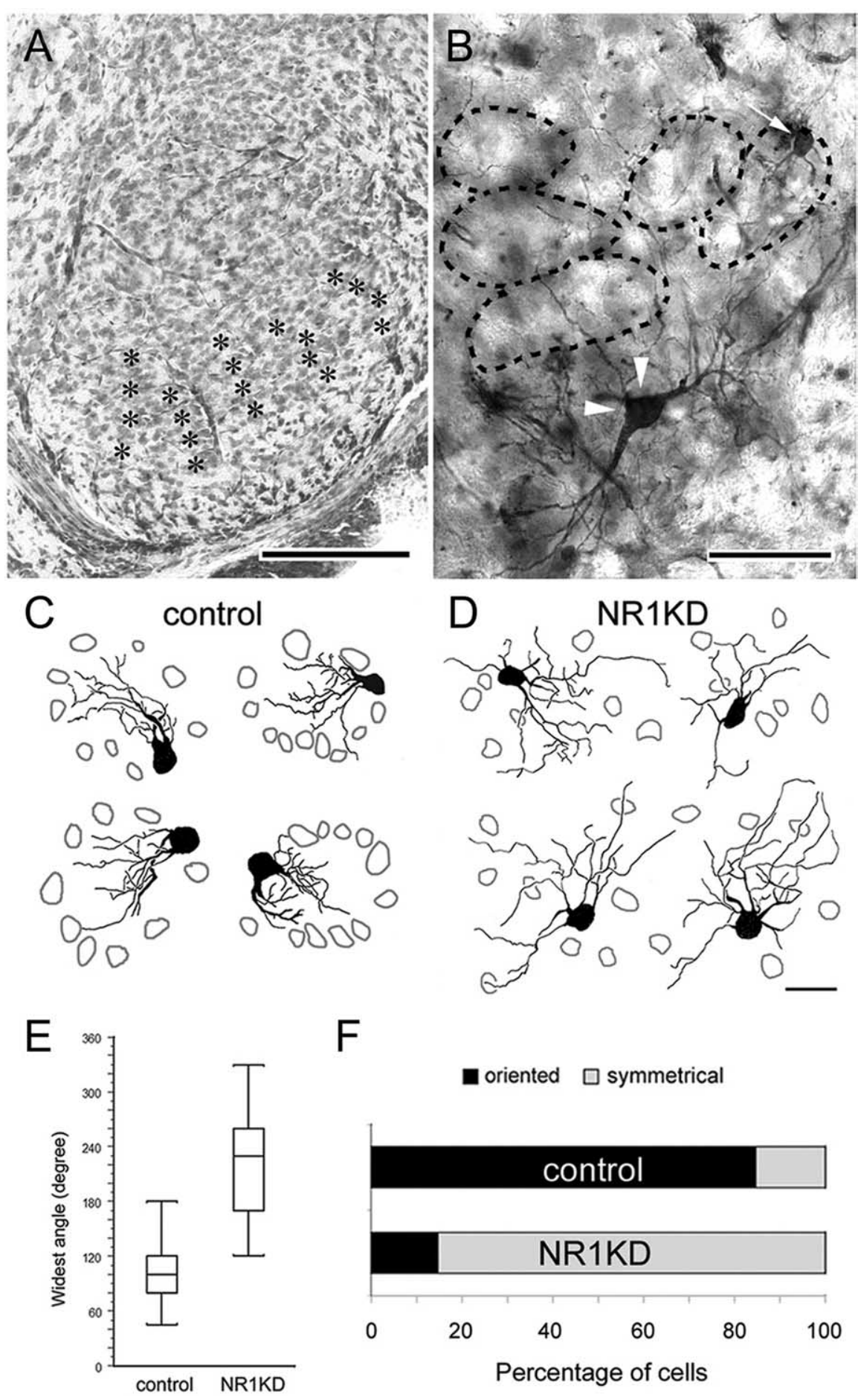

F

oriented $\square$ symmetrical

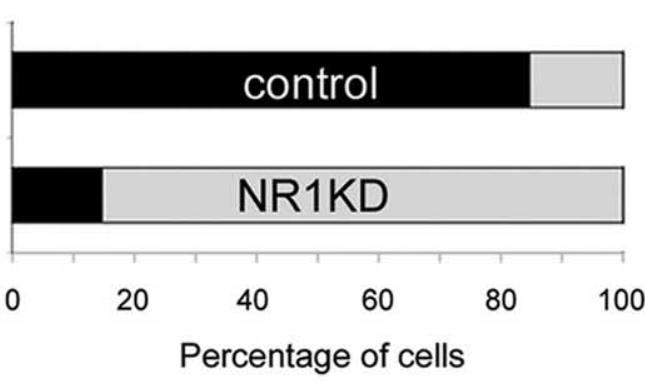

Figure 4. Altered dendritic differentiation and patterning in NRIKD mice. A, Photomicrograph of a Nissl-stained section showing the barrelettes (asterisks) in ventral PrV of a P14 control mouse. B, Golgi-stained barrelette (arrow) and interbarrelette (arrowheads) cells. In both photomicrographs, lateral is to the right, and dorsal is to the top. C, D, Examples of P14 barrelette neurons drawn with camera lucida. In control mice ( $\boldsymbol{C}$, each "barrelette unit" consists of a relatively cell-free "center" and a cell-dense "wall" (gray cellular outlines). Barrelette neurons in control PrV orient their dendrites mainly toward the barrelette center (C). The dendrites of barrelette neurons in NR7KD PrV are longer and show no specific orientation (D). Scale bars: $A, 200$ $\mu \mathrm{m} ; \boldsymbol{B}, 100 \mu \mathrm{m} ; \boldsymbol{C}, \boldsymbol{D}, 20 \mu \mathrm{m} . \boldsymbol{E}, \boldsymbol{F}$, Dendritic orientation of barrelette cells. $\boldsymbol{E}$, The widest angle between two furthest dendrites is measured. Compared with controls, barrelette neurons of NRTKD mice have wider dendritic distribution, averaging $102^{\circ}$ in control and $218^{\circ}$ in NRTKD. The difference between control and NRTKD is significant ( $p<0.0001$; Student's $t$ test). $\boldsymbol{F}$, The percentage of terminal endings that fall into the upper quadrant is calculated. A neuron with $>75 \%$ of its dendrites in one quadrant is considered "oriented," otherwise it is considered "symmetrical." A total of $85 \%$ of control barrelette neurons are oriented, whereas $85 \%$ of NRTKD barrelette neurons are symmetrical. 
Table 1. Morphometric analyses of barrelette neurons

\begin{tabular}{lllllll}
\hline & $\begin{array}{l}\text { Soma size } \\
\left(\mu \mathrm{m}^{2}\right)\end{array}$ & $\begin{array}{l}\text { Covered area } \\
\left(\mu \mathrm{m}^{2}\right)\end{array}$ & $\begin{array}{l}\text { Primary } \\
\text { dendrites }\end{array}$ & $\begin{array}{l}\text { Bifurcation } \\
\text { nodes }\end{array}$ & $\begin{array}{l}\text { Terminal } \\
\text { endings }\end{array}$ & $\begin{array}{l}\text { Dendritic } \\
\text { orders }\end{array}$ \\
\hline Control & $81.2 \pm 3.2$ & $618 \pm 39.7$ & $2.7 \pm 0.1$ & $17 \pm 0.8$ & $20 \pm 0.8$ & $7.6 \pm 0.3$ \\
NR1KD & $84.9 \pm 3.2$ & $2093 \pm 121.0^{* *}$ & $3.7 \pm 0.2^{* *}$ & $14 \pm 0.8^{*}$ & $18 \pm 0.9$ & $6.1 \pm 0.2^{* *}$ \\
\hline
\end{tabular}

Results are mean \pm SEM. Significant differences are indicated by asterisks ( ${ }^{*} p<0.05$; ${ }^{* *} p<0.001$; Student's $t$ test).

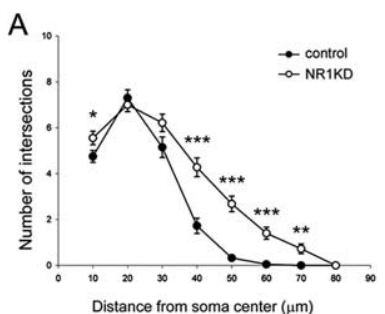

D

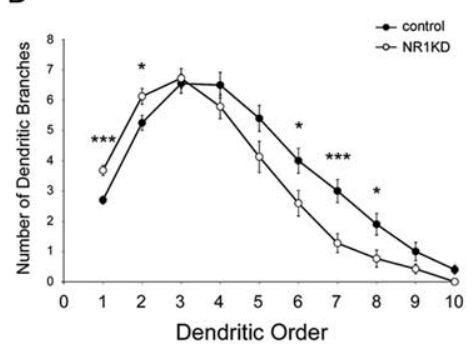

$B$

E

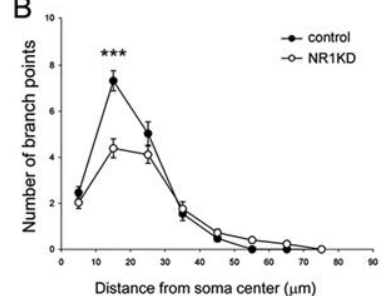

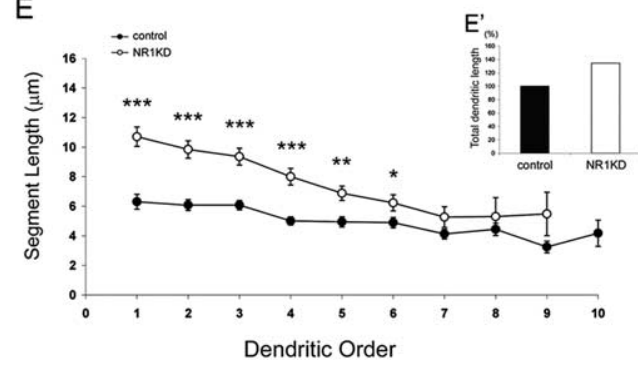

Figure 5. Dendritic complexity and branching pattern of barrelette neurons. $A, N R 1 K D$ barrelette neurons have a larger number of intersections at the most proximal and distal parts. $\boldsymbol{B}$, Both control and NR1KD barrelette neurons bifurcate their dendrites proximally. In control neurons, the distribution curve drops sharply from the peak. There are fewer dendritic bifurcations in NR1KD neurons; thus, the distribution curve of NR1KD neurons is more flat. C, Most of the dendritic terminals of control and NRTKD barrelette neurons are located between 10 and $40 \mu \mathrm{m}$ from the soma center, and the peak is between 20 and $30 \mu \mathrm{m}$. However, in NR1KD barrelette neurons, some of the terminal endings are located beyond $50 \mu \mathrm{m}$ from the soma. $D$, Dendrites of NR1KD barrelette neurons have more branches at lower orders, whereas the branch number is reduced significantly at higher orders in comparison with the controls. $\boldsymbol{E}$, Comparisons of the segment length of each dendritic order show that in NR1KD neurons, segments of the first to sixth orders are significantly longer, resulting in a $35 \%$ increase in total dendritic length $\left(\boldsymbol{E}^{\prime}\right)$. Results are mean \pm SEM. Significant differences are indicated by asterisks ( ${ }^{*} p<0.05 ;{ }^{* *} p<0.01$; ${ }^{* * *} p<0.001$; Student's $t$ test).

These changes in afferent organization and rearrangement of barrelette cell dendritic trees in infraorbital nerve-lesioned postnatal rats are similar to our present observations in NR1KD mice. After structural modification, single barrelette neurons receive more synaptic inputs than normal PrV (Lo and Erzurumlu, 2004). These effects are seen in wild-type animals with normal levels of NR1 expression in the PrV. In contrast to the observations reported here, morphological alterations seen after peripheral nerve lesions are not as robust. In mutant mice, in addition to patterning defects, whisker afferent terminal fields expand fivefold more, and barrelette cell dendrites grow longer distances, even though a full set of whiskers are present on the snout and their innervation by the infraorbital nerve and its topographic projections to the brainstem are not altered. Collectively, results from lesion studies in normal animals and NMDAR-deficient animals underscore the role of peripheral inputs and neural activity in sculpting whisker afferent terminals and dendritic trees of their postsynaptic partners.

In NMDAR-deficient mice, the gross topography of the whisker afferents in the trigeminal pathway is maintained, but their terminal arbor growth is exaggerated, and patterning into discrete clusters is impaired. Postsynaptic dendritic defects could be a passive response to expanded presynaptic terminal arbors. In cortexspecific NR1 KO mice, whisker-specific

tain their intrinsic membrane properties and normal synaptic transmission, albeit reduced NMDA currents. By virtue of the expansion of whisker afferent terminal arbors and aberrant organization of barrelette cell dendrites, individual barrelette neurons, which normally respond to inputs from a single whisker, must now respond to overlapping inputs from multiple whiskers and subsequently relay this information to the ventrobasal thalamus and primary somatosensory cortex, where whisker-related patterns also fail to develop. Although these structural changes implicate functional alterations in synaptic transmission between the PrV and thalamus and subsequently in the barrel cortex, this prediction remains to be tested by electrophysiological recordings from upstream targets.

Patterning of neural connections along the rodent whiskerbarrel pathway depends on inputs from the sensory periphery during a critical period in development. When the whisker follicles or the infraorbital nerve innervating them are damaged at early postnatal ages (to P3), the barrelette patterns (and upstream neural patterns) are predictably altered or abolished (Woolsey, 1990; O'Leary et al., 1994). Excitatory and inhibitory circuits in the barrelette region of the PrV are established by P1 (Lo et al., 1999). Infraorbital nerve lesion at birth does not change membrane properties or synaptic transmission of PrV cells (Lo and Erzurumlu, 2001, 2002), much like that reported here for NMDAR-deficient mice. However, whisker afferent terminals lose their patchiness (Bates and Killackey, 1985), and barrelette cells lose their dendritic orientation (Lo and Erzurumlu, 2002). thalamocortical axon arbors are also expansive but display localized concentrations of terminal boutons (Lee et al., 2005), yet even in these regions of terminal concentrations, layer IV spiny stellate (barrel) cells fail to orient their dendrites. Instead, they develop longer, nonoriented dendritic trees (Datwani et al., 2002). During the process of concurrent addition and pruning of presynaptic terminal and postsynaptic dendritic branches, NMDAR-mediated activity could act as a stop/stabilization signal, thereby contributing to their focalization and patterning. In the mouse barrel cortex, expansion of terminal fields of thalamocortical axons has also been noted for other mutants such as the barrelless (brl; adenylyl cyclase type $1 \mathrm{KO}$ ) and monoamine oxidase A (MAOA) KO mice, which show cortical pattern defects but not in subcortical trigeminal centers (Welker et al., 1996; Rebsam et al., 2002). Although details of dendritic differentiation of barrel cells in these mutants have not been charted, it is likely that other molecules, independently or cooperatively with NMDARs, can also affect restriction and patterning of whiskerrelated afferent terminals. A recent study showed that mice lacking Drg11, a homeodomain transcription factor, exhibit trigeminal pattern defects strikingly similar to those observed in NR1KD mice (Ding et al., 2003). These mice fail to develop whiskerrelated patterns in the PrV, ventroposteromedial thalamic nucleus, and the somatosensory cortex. Single-whisker afferent terminal and barrelette cell dendritic differentiation analyses in these mice are not yet available, but clearly this transcription 
factor is essential for proper development of and barrelette patterning in the PrV and its upstream targets. Presently, there is no known relationship between Drg11 and NMDA receptors.

Comparison of presynaptic arbor differentiation between control, NR1KO, and NR1KD animals suggests the presence of a threshold level of NMDA receptor function below which morphological differentiation is affected, whereas synaptic transmission is not. Presently, this threshold and the signaling pathways downstream from NMDA receptors used in clustering of whisker afferent terminals and dendrites of their postsynaptic partners are not known. Morphological defects at both the presynaptic and postsynaptic sites indicate active communication via anterograde and retrograde signaling mechanisms. Nitric oxide (NO), brain-derived neurotrophic factor (BDNF), and arachidonic acid (AA) have all been implicated as potential retrograde signals that might affect structural differentiation of presynaptic terminals in other systems (for review, see Schmidt, 2004). To our knowledge, none of these molecules are known to be specifically expressed by PrV barrelette neurons. NO synthase distribution in the rat brainstem trigeminal complex does not correspond to the thalamic projection (barrelette) neurons (Dohrn et al., 1994), and nicotinamide adenine dinucleotide phosphate-diaphorase-positive elements seen in the PrV are of dorsal raphe origin (Simpson et al., 2003). BDNF expression in the developing mouse PrV has not been detailed, although a subset of trigeminal ganglion cells are endowed with tyrosine kinase receptor B and depend on survival for BDNF (Ernfors et al., 1994). Nothing is known about the potential role of $\mathrm{AA}$ as a retrograde messenger in this system.

We do not know whether defects in NR1KD mice arise from reduced levels of NMDAR function presynaptically, postsynaptically, or both. One line of preliminary evidence suggests that levels of postsynaptic NMDAR function rather than presynaptic plays the central role. In NR1KD mice, there are differential levels of expression of $N R 1$ between the PrV and spinal trigeminal nucleus interpolaris, the latter having higher expression (Iwasato et al., 1997). Whisker afferents bifurcate as they enter the central trigeminal tract, and one branch heads for the PrV and the other for the spinal trigeminal nucleus where they both form whiskerspecific patterns (Jacquin et al., 1993). In NR1KD mice, these terminals in the spinal trigeminal nucleus interpolaris form rudimentary, patterned arbors, whereas their sister branches fail to form any patterns in the PrV (L.-J. Lee and R. S. Erzurumlu, unpublished observations). Thus, postsynaptic NMDAR signaling is more likely to play a significant role in neuronal patterning. Observations from cortex-specific NR1 KO mice also confirm this idea. In these mutants, thalamocortical afferents with intact NMDARs develop exuberant terminal arbors in the barrel cortex, and layer IV stellate cells fail to orient their dendrites and grow longer dendritic segments (Lee et al., 2005).

During the past several years, a number of molecules downstream from NMDAR-initiated $\mathrm{Ca}^{2+}$ entry into neurons and those that act cooperatively with NMDARs at the postsynaptic density have been noted in modulating dendritic cytoskeletal dynamics, spine morphology, and presynaptic terminal sculpting (Carroll and Zukin, 2002; Scheiffele, 2003; Wenthold et al., 2003). Calcium/calmodulin-dependent protein kinase II (Wu and Cline, 1998; Zou and Cline, 1999), neuroligins and neurexins (Nguyen and Südhof, 1997; Scheiffele et al., 2000), and Eph proteins (Dalva et al., 2000) are among these. It remains to be determined how these molecules, or others yet to be identified, participate in choreography of neuronal patterning and underlying communication between the whisker-specific afferent terminals and their partners in the PrV.

\section{References}

Bates CA, Killackey HP (1985) The organization of the neonatal rat's brainstem trigeminal complex and its role in the formation of central trigeminal patterns. J Comp Neurol 240:265-287.

Belford GR, Killackey HP (1980) The sensitive period in the development of the trigeminal system of the neonate rat. J Comp Neurol 193:335-350.

Carroll RC, Zukin RS (2002) NMDA-receptor trafficking and targeting: implications for synaptic transmission and plasticity. Trends Neurosci 25:571-577.

Dalva MB, Takasu MA, Lin MZ, Shamah SM, Hu L, Gale NW, Greenberg ME (2000) EphB receptors interact with NMDA receptors and regulate excitatory synapse formation. Cell 103:945-956.

Datwani A, Iwasato T, Itohara S, Erzurumlu RS (2002) NMDA receptordependent pattern transfer from afferents to postsynaptic cells and dendritic differentiation in the barrel cortex. Mol Cell Neurosci 21:477-492.

Ding YQ, Yin J, Xu HM, Jacquin MF, Chen ZF (2003) Formation of whisker-related principal sensory nucleus-based lemniscal pathway requires a paired homeodomain transcription factor, Drg11. J Neurosci 23:7246-7254.

Dohrn CS, Mullett MA, Price RH, Beitz AJ (1994) Distribution of nitric oxide synthase-immunoreactive interneurons in the spinal trigeminal nucleus. J Comp Neurol 346:449-460.

Durham D, Woolsey TA (1984) Effects on neonatal whisker lesions on mouse central trigeminal pathways. J Comp Neurol 233:424-447.

Ernfors P, Lee KF, Jaenisch R (1994) Mice lacking brain-derived neurotrophic factor develop with sensory deficits. Nature 368:147-150.

Erzurumlu RS, Jhaveri S (1990) Thalamic axons confer a blueprint of the sensory periphery onto the developing rat somatosensory cortex. Dev Brain Res 56:229-234.

Erzurumlu RS, Jhaveri S (1992) Trigeminal ganglion cell processes are spatially ordered prior to the differentiation of the vibrissa pad. J Neurosci 12:3946-3955.

Iwasato T, Erzurumlu RS, Huerta PT, Chen DF, Sasaoka T, Ulupinar E, Tonegawa S (1997) NMDA receptor-dependent refinement of somatotopic maps. Neuron 19:1201-1210.

Jacquin MF, Renehan WE, Rhoades RW, Panneton WM (1993) Morphology and topography of identified primary afferents in trigeminal subnuclei principalis and oralis. J Neurophysiol 70:1911-1936.

Killackey HP, Fleming K (1985) The role of the principal sensory nucleus in central trigeminal pattern formation. Dev Brain Res 22:141-145.

Kutsuwada T, Sakimura K, Manabe T, Takayama C, Katakura N, Kushiya E, Natsume R, Watanabe M, Inoue Y, Yagi T, Aizawa S, Arakawa M, Takahashi T, Nakamura Y, Mori H, Mishina M (1996) Impairment of suckling response, trigeminal neuronal pattern formation, and hippocampal LTD in NMDA receptor epsilon 2 subunit mutant mice. Neuron 16:333-344.

Lee L-J, Erzurumlu RS (2005) Altered parcellation of neocortical somatosensory maps in NMDA receptor-deficient mice. J Comp Neurol, in press.

Lee L-J, Iwasato T, Itohara S, Erzurumlu RS (2005) Exuberant thalamocortical axon arborization in cortex-specific NMDAR1 knockout mice. J Comp Neurol, in press.

Li Y, Erzurumlu RS, Chen C, Jhaveri S, Tonegawa S (1994) Whisker-related neuronal patterns fail to develop in the trigeminal brainstem nuclei of NMDAR1 knockout mice. Cell 76: 427-437.

Lo F-S, Erzurumlu RS (2001) Neonatal deafferentation does not alter membrane properties of trigeminal nucleus principalis neurons. J Neurophysiol 85:1088-1096.

Lo F-S, Erzurumlu RS (2002) L-type calcium channel-mediated plateau potentials in barrelette cells during structural plasticity. J Neurophysiol 88:794-801.

Lo F-S, Erzurumlu RS (2004) More trigeminal inputs converge on single barrelette neurons in denervated nucleus principalis $(\mathrm{PrV})$ of neonatal rats. Soc Neurosci Abstr 34:615.7.

Lo F-S, Guido W, Erzurumlu RS (1999) Electrophysiological properties and synaptic responses of cells in the trigeminal principal sensory nucleus of postnatal rats. J Neurophysiol 82:2765-2775.

Ma PM (1993) Barrelettes-architectonic vibrissal representations in the brainstem trigeminal complex of the mouse. II. Normal post-natal development. J Comp Neurol 327:376-397.

Ma PM, Woolsey TA (1984) Cytoarchitectonic correlates of the vibrissae in the medullary trigeminal complex of the mouse. Brain Res 306:374-379.

Nguyen T, Südhof TC (1997) Binding properties of Neuroligin 1 and Neur- 
exin $1 \beta$ reveal function as heterophilic cell adhesion molecules. J Biol Chem 272:32-39.

Ohara PT, Havton LA (1994) Dendritic architecture of rat somatosensory thalamocortical projection neurons. J Comp Neurol 341:159-171.

O’Leary DDM, Ruff NL, Dyck RH (1994) Development, critical period plasticity, and adult reorganizations of mammalian somatosensory systems. Curr Opin Neurobiol 4:535-544.

Rebsam A, Seif I, Gaspar P (2002) Refinement of thalamocortical arbors and emergence of barrel domains in the primary somatosensory cortex: a study of normal and monoamine oxidase a knock-out mice. J Neurosci 22:8541-8552.

Scheiffele P (2003) Cell-cell signaling during synapse formation in the CNS. Annu Rev Neurosci 26:485-508.

Scheiffele P, Fan J, Choih J, Fetter R, Serafini T (2000) Neuroligin expressed in nonneuronal cells triggers presynaptic development in contacting axons. Cell 101:657-669.

Schmidt JT (2004) Activity-driven sharpening of the retinotectal projection: the search for retrograde synaptic signaling pathways. J Neurobiol 59:114-133.

Senft SL, Woolsey TA (1991) Growth of thalamic afferents into mouse barrel cortex. Cereb Cortex 1:308-335.

Sholl DA (1953) Dendritic organization in the neurons of the visual cortex and motor cortices of the cat. J Anat 87:387-406.

Simpson KL, Waterhouse BD, Lin RC (2003) Differential expression of ni- tric oxide in serotonergic projection neurons: neurochemical identification of dorsal raphe inputs to rodent trigeminal somatosensory targets. J Comp Neurol 466:495-512.

Stainier DY, Gilbert W (1990) Pioneer neurons in the mouse trigeminal sensory system. Proc Natl Acad Sci USA 87:923-927.

Van Der Loos H (1976) Barreloids in mouse somatosensory thalamus. Neurosci Lett 2:1-6.

Welker E, Armstrong-James M, Bronchti G, Ourednik W, GheorghitaBaechler F, Dubois R, Guernsey DL, Van der Loos H, Neumann PE (1996) Altered sensory processing in the somatosensory cortex of the mouse mutant barrelless. Science 271:1864-1867.

Wenthold RJ, Prybylowski K, Standley S, Sans N, Petralia RS (2003) Trafficking of NMDA receptors. Annu Rev Pharmacol Toxicol 43:335-358.

Woolsey TA (1990) Peripheral alteration and somatosensory development. In: Development of sensory systems in mammals (Coleman EJ, ed), pp 461-516. New York: Wiley.

Woolsey TA, Van Der Loos H (1970) The structural organization of layer IV in the somatosensory region (SI) of mouse cerebral cortex. Brain Res 17:204-242.

Wu GY, Cline HT (1998) Stabilization of dendritic arbor structure in vivo by CaMKII. Science 279:222-226.

Zou DJ, Cline HT (1999) Postsynaptic calcium/calmodulin-dependent protein kinase II is required to limit elaboration of presynaptic and postsynaptic neuronal arbors. J Neurosci 19:8909-8918. 